\title{
The role of atenolol in the modulation of the expression of genes encoding pro- (caspase-1) and anti- (Bcl2L1) apoptotic proteins in endothelial cells exposed to intestinal ischemia and reperfusion in rats ${ }^{1}$
}

Murched Omar Taha', Thaís de Melo Alexandre e Silva", Keimy Saori Ota", Wander Junqueira Vilela", Ricardo Santos Simões"', Alberto Starzewski Junior'v, Djalma José Fagundes ${ }^{\mathrm{V}}$

'PhD, Associated Professor, Surgical Technique and Experimental Surgery, Universidade Federal de São Paulo (UNIFESP), Brazil. Conception and design of the study, critical revision, final approval.

"Graduate student, Medical School, Universidade Anhembi Morumbi, Sao Paulo-SP, Brazil. Acquisition of data, technical procedures, manuscript preparation.

I'PhD, Department of Morphology and Genetic, UNIFESP, Sao Paulo-SP, Brazil. Analysis of data, manuscript preparation and writing.

IVMD, Assistant Professor, Medical School, Universidade Anhembi Morumbi, Sao Paulo-SP, Brazil. Conception of the study, critical revision.

VPhD, Full Professor, Division of Surgical Techniques and Experimental Surgery, Department of Surgery, UNIFESP, Sao Paulo-SP, Brazil. Conception and design of the study, critical revision, final approval.

\section{Abstract}

Purpose: To investigate the role of atenolol in the gene expression of caspase 1 (Casp1) and $\mathrm{Bcl} 2 \mathrm{~L} 1$ on vascular endothelium of rat intestine after ischemia and reperfusion (IR).

Methods: Eighteen adult male Wistar rats were randomly divided into 3 groups $(n=6)$ : SG (Sham group): no clamping of the superior mesenteric artery; IRG: IR plus saline group: IRG+At: IR plus Atenolol group. Rats from IRG and IRG+At were subjected to 60 min of intestinal ischemia and $120 \mathrm{~min}$ of reperfusion. Atenolol $(2 \mathrm{mg} / \mathrm{kg})$ or saline were injected in the femoral vein $5 \mathrm{~min}$ before ischemia, $5 \mathrm{~min}$ and $55 \mathrm{~min}$ after reperfusion. Thereafter, intestinal segments were appropriately removed and processed for Endothelial Cell Biology Rat RT2 Profiler PCR Array.

Results: the anti-apoptotic Bcl2L1 gene expression was significantly down-regulated (-1.10) in the IRG and significantly up-regulated in the IRG+At (+14.15). Meanwhile, despite Casp1 gene expression was upregulated in both groups, it was significantly higher in the IRG (+35.06) than the IRG+At (+6.68).

Conclusions: Atenolol presents antiapoptotic effects on rat intestine subjected to IR partly by the up-regulation of the anti-apoptotic Bcl2L1 gene expression. Moreover, atenolol can mitigate the pro-apoptotic and pro-inflammatory effects of Casp1 gene on rat intestine after IR.

Key words: Mesenteric Ischemia. Atenolol. Gene Expression. Ischemia. Reperfusion. Apoptosis. Rats. 


\section{Introduction}

Ischemia/reperfusion (I/R) injury is a frequent phenomenon that is associated to high morbidity and mortality ${ }^{1-4}$. It constitutes as part of pathophysiology of diseases such as intestinal obstruction, acute mesenteric ischaemia, hypovolemic and septic shock and necrotizing colitis. Moreover, $\mathrm{I} / \mathrm{R}$ occurs in several daily medical situations including major operations and organ transplantations ${ }^{1,2,4}$.

It is known that blood reperfusion is essential to the ischemic tissue, in order to prevent irreversible cell damage. However, the reoxygenation may worst cell damage by leading to the formation of reactive oxygen species (ROS), which initiates a complex cascade of events that culminate in additional tissue injury, promoting immediate cell death (necrosis), programed cell death (apoptosis) and alteration of cellular phenotype ${ }^{5-7}$.

Several drugs, such as beta blockers, have been proposed as modulating agents to minimize I/R injury. It was demonstrated that $\beta 1$ adrenergic receptors are activated during I/R by catecholamines. Increased ROS production and apoptosis are thought to be mediated by the $\beta 1$ adrenergic receptors, both in-vitro and in-vivo ${ }^{8}$.

Previous studies showed that atenolol, a selective $\beta 1$ sympathetic receptor blocker, used to treat cardiovascular diseases, has cytoprotective effects when administered intravenously and attenuates intestinal injury caused by $\mathrm{I} / \mathrm{R}^{9}$. However, the cytoprotective mechanisms of atenolol against $\mathrm{I} / \mathrm{R}$ are not well understood.

Therefore, this experimental study was designed to evaluate the effects of atenolol on gene expression of rat intestine tissue submitted to I/R.

\section{Methods}

The study was designed as a randomized controlled trial with a blinded assessment of the outcome and was approved by the Ethics Committee in Research, Universidade Federal de São Paulo (UNIFESP). All animal procedures were carried out according to the recommendations of the international legislations on animal protection.

Eighteen adult male Wistar-EPM1 rats with body weight of $250 \mathrm{~g}$ to $300 \mathrm{~g}$ were provided by the Center for the Development of Experimental Models for Medicine and Biology - (CEDEME-UNIFESP). The animals were housed under controlled temperature and light condition ( $22^{\circ} \mathrm{C}, 12 \mathrm{~h}$ light/dark cycle) with free access to water and standard pellet chow until $6 \mathrm{~h}$ prior to the surgical procedures.

\section{Anaesthesia and surgical procedures}

Under intramuscular anaesthesia (80 $\mathrm{mg} . \mathrm{kg}^{-1}$ ketamine and $10 \mathrm{mg} . \mathrm{kg}-1$ xylazine), a median laparotomy was performed in order to exposure the superior mesenteric vessels. The animals were then randomly assigned into the following groups: Sham group (SG, $n=10)$ : without clamping of superior mesenteric artery; Ischemia and reperfusion group (IRG, $n=10)$ : clamping of superior mesenteric vessels plus saline solution; Ischemia and reperfusion plus Atenolol group (IRG+At, $n=10)$ : clamping of superior mesenteric vessels plus $2 \mathrm{mg} / \mathrm{kg}$ of Atenolol. The rats from IRG and IRG+At were subjected to $60 \mathrm{~min}$ of intestinal ischemia followed by $120 \mathrm{~min}$ of reperfusion. Atenolol or saline solution $(0.5 \mathrm{ml})$ was injected in the femoral vein $5 \mathrm{~min}$ before ischemia, $5 \mathrm{~min}$ and 55 min after reperfusion.

\section{Intestinal samples and gene expression} procedures

Intestinal segments $(3 \mathrm{~cm})$ were removed at $20 \mathrm{~cm}$ from the duodenumjejunum flexure, opened longitudinally, gently washed in saline solution, wrapped in 
aluminium foil, and immediately flash-frozen in liquid nitrogen. The tissue samples were submitted to the Endothelial Cell Biology Rat $\mathrm{RT}^{2}$ Profiler ${ }^{\mathrm{TM}} \mathrm{PCR}$ microarray method (SA Biosciences-Qiagen Co, USA). Briefly, total RNA was extracted from tissues using Trizol reagent (Life Technologies, USA) and purified using an RNeasy MiniKit (SA Biosciences - Qiagen Co, USA). Concentration of each total RNA sample was determined by spectrophotometry, and the quality was assessed by electrophoresis on $2 \%$ agarose gels. The mRNA of each sample was converted into cDNA using the $\mathrm{RT}^{2}$ First Strand Kit (SA Biosciences - Qiagen Co, USA). Equal amounts of cDNA and the Master Mix $\mathrm{SYBR}^{\circ}$ Green qPCR Mastermix (SA Biosciences - Qiagen Co, USA) were added to each well of the PCR microarray plate. This 96-well plate contains five housekeeping genes (ACTB, Gapdh, Hsp90ab1, Hprt1, and Gusb), three positive PCR controls used to determine the efficiency of reaction, three reverse transcriptase controls and one negative control to detect the presence of genomic DNA contamination. For each PCR reaction, the instrument's software (MxPro Equipment Real Time Systems, Stratagene, GE, Co, USA) Data normalisation was based on correcting all threshold cycle $(\mathrm{Ct})$ values for the average $\mathrm{Ct}$ values of the average of housekeeping genes and the comparisons was made by calculating fold changes in gene expression from the raw Ct data using the $\Delta \Delta \mathrm{Ct}$ method. Gene expression data for each sample was evaluated in triplicate. The gene expression results are presented as positive/upregulation expression (IRG $>\mathrm{GC}$ ) or negative/ down-regulation expression (IRG<CG). The numbers represent how many times each gene was expressed above [plus sign (+)] or below [minus sign (-)]. The software established that the results three-fold above (over expression) or three-fold below (hypo expression) the threshold allowed by the algorithm $\left[2^{\wedge}(\Delta \Delta \mathrm{Ct})\right]$ are biologically relevant. The same procedure was performed between IRG+At and $\mathrm{SG}^{10-}$ 12. The method used is contained in the spreadsheet for PCR Array Data Analysis v3.3 (SA Biosciences - Qiagen Co, USA $)^{10}$.

\section{Genes of choice}

From 84 genes allowed by the Endothelial Cell Biology Rat $\mathrm{RT}^{2}$ Profiler $^{\mathrm{TM}}$ PCR microarray method, the genes that encode the proteins Bcl2L1 and Caspase 1 (Casp1) were selected. The choice criterium considered the statistical significance of the genic expression between the IRG group and IRG+At group in comparison to IR group.

\section{Statistical analysis}

Gene expression data for each sample was evaluated in triplicate. Analysis of variance (ANOVA) and the Tukey post hoc test were performed to validate the homogeneity of the reaction of expression of each gene $(p<0.05)$.

\section{Results}

Our results of the two selected genes (Bcl2L1 and Casp1) showed a statistical significance between the group submitted only to the ischemia/reperfusion (IRG), in comparison to the IRG+At (Table 1). The anti-apoptotic Bcl2L1 gene expression was significantly $(p<0.05)$ down-regulated in the IRG $(-1.10)$ and significantly $(p<0.05)$ upregulated in the IRG+At (+14.15). On the other hand, despite the apoptotic CASP1 gene expression was up-regulated in both groups, it was significantly $(p<0.05)$ higher in the IRG $(+35.06)$ when compared to IRG+At $(+6.68)$ (Table 1). 
Table 1 - Gene expression of Bcl2L1 and Casp1 from sham (SG), ischemia and reperfusion (IRG) and ischemic and reperfusion plus Atenolol (IRG+At) groups. Significant values of fold up (+) or down (-) regulation was marked in bold $\left[2^{\wedge}(-\right.$ Delta $\mathrm{Ct}]$.

\begin{tabular}{llllll} 
& & & \multicolumn{3}{c}{ GROUPS } \\
& Bank & Symbol & IRG & IRG+At & P value \\
\hline A09 & NM_031535 & Bcl2L1 & -1.10 & $+14.15^{*}$ & 0.00014 \\
A12 & NM_012762 & Casp1 & +35.06 & $+6.68^{*}$ & 0.00005 \\
\hline
\end{tabular}

$\left({ }^{*}\right) p<0.05$

\section{- Discussion}

The mechanisms involving intestinal I/R are not entirely clear. However, it is known to be activated by many cellular and extracellular factors ${ }^{14}$. On the other hand, assuming that gene expression is quantitatively related to the need for proteins encoded by specific genes, the aim of this study was to investigate the expression of genes encoding pro and antiapoptotic proteins in rat intestines after $\mathrm{I} / \mathrm{R}$, as well as the effects of Atenolol as a modulator of these genes.

We hypothesized that during the intestinal ischemia/reperfusion, ROS causes cell changes including cell membrane damages that can activate genes encoding anti- and proapoptotic proteins such as Bcl2L1 and caspase 1 , respectively. In addition, it is expected that Atenolol can promote modulating effects on the gene expression that encode these two proteins ${ }^{13}$.

The anti-apoptotic Bcl2L1 protein, for instance, is a potent inhibitor of cell death by means of preventing activation of caspases. This protein has been shown to regulate cell death by binding and blocking the voltagedependent anion channel (VDAC), thereby preventing the release of the caspase activator cytochrome $\mathrm{C} 1$ (CYC1), from the mitochondrial membrane ${ }^{14}$. Decreased of Bcl2L1 can trigger a caspase cascade that ultimately leads to apoptosis, whereas increased Bcl2L1 can inhibit apoptosis $^{15}$. The gene expression of Bcl2L1 was significantly up regulated in IRG+Atenolol group $(+14,15)$ in comparison to IRG $(-1,10)$, which indicates that Atenolol presents antiapoptotic effects that could mitigate the intestine damages caused by ischemia and reperfusion.

The Casp1 gene encodes a protein that is a member of the cysteine-aspartic acid protease family (known as caspase family). It was identified by its ability to proteolytically cleave and activate the inactive precursor of interleukin-1, a cytokine involved in several processes such as inflammation, septic shock, and wound healing. It also plays a pivotal role in the cascade that leads to apoptosis in several organs and tissues, including the epithelial cells of intestine. Once activated, the inflammatory response increases expression of Caspase-1 by a positive feedback that worse the response ${ }^{16}$.

Despite we observed that Casp1 gene expression was up-regulated in both IRG and IRG+At groups, it was significantly higher in the IRG when compared to IRG+At. These results indicate that Atenolol could alleviate the intestine damages after ischemia and reperfusion, by reducing both inflammation and apoptosis.

\section{- Conclusions}

Our results demonstrate that exogenous atenolol is associated with antiapoptotic effects on the rat intestine subjected to IR by, in part, the up-regulation of Bcl2L1 gene expression. In addition, Atenolol can mitigate 
The role of atenolol in the modulation of the expression of genes encoding pro- (caspase-1) and anti- (Bcl2L1) apoptotic proteins in endothelial cells exposed to intestinal ischemia and reperfusion in rats Taha MO et al.

the pro-apoptotic and inflammatory effects of CASP1 gene in rat intestine after ischemia and reperfusion.

\section{References}

1. Oliveira TR, Oliveira GF, Simões RS, Feitosa SM, Tikazawa EH, Monteiro HP, Fagundes DJ, Taha MO. The expression of endothelial and inducible nitric oxide synthase and apoptosis in intestinal ischemia and reperfusion injury under the action of ischemic preconditioning and pentoxifylline. Acta Cir Bras. 2017;32(11):935-48. doi: 10.1590/s0102-865020170110000005.

2. Bonservizi WGS, Koike MK, Saurim R, Felix GA, da Silva SM, Montero EF, Taha MO. Ischemic preconditioning and atenolol on lung injury after intestinal ischemia and reperfusion in rats. Transplant Proc. 2014;46:1862-6. doi: 10.1016/j.transproceed.2014.05.054.

3. Jácome DT, Abrahão MS, Morello RJ, Martins $\mathrm{JL}$, Medeiros AC, Montero EFS. Different intervals of ischemic preconditioning on small bowel ischemia-reperfusion injury in rats. Transplant Proc. 2009;41(3):827-9. doi: 10.1016/j.transproceed.2009.01.071.

4. Taha MO, Ferreira RM, Taha NSA, Monteiro HP, Caricati-Neto A, Fagundes DJ. Heparin modulates the expression of genes encoding pro and anti-apoptotic proteins in endothelial cells exposed to intestinal ischemia and reperfusion in rats. Acta Cir Bras. 2014;29(7):445-9. doi: 10.1590/ S0102-86502014000700006.

5. Wu M, Chen M, Sang S, Hou LL, Tian ML, Li K, Lv FQ. Protective effects of hydrogen rich water on the intestinal ischemia/reperfusion injury due to intestinal intussusception in a rat model. Med Gas Res. 2017;7(2):101-6. doi: 10.4103/2045-9912.208515.

6. Liu P G, He S Q, Zhang Y H, Wu J. Protective effects of apocynin and allopurinol on ischemia/reperfusion-induced liver injury in mice. World J Gastroenterol. 2008;14(18):2832-7. doi: 10.3748/ wjg.14.2832.

7. Tong F, Dong B, Chai R, Wang Y4, Chen S, Zhou X, Liu D. Simvastatin nanoparticles attenuated intestinal ischemia/reperfusion injury by downregulating BMP4/COX2 pathway in rats. Int $\mathrm{J}$ Nanomedicine.
2017;12:2477-88. doi: 10.2147/IJN. S126063.

8. Wang $X$, Cheng $Y$, Xue $H$, Yue $Y$, Zhang $W$, Li $X$. Fargesin as a potential $\beta 1$ adrenergic receptor antagonist protects the hearts against ischemia/reperfusion injury in rats via attenuating oxidative stress and apoptosis. Fitoterapia. 2015;105:16-25. doi: 10.1016/j.fitote.2015.05.016.

9. Oztürk T, Vural K, Tuğlu I, Var A, Kurdal T, Aydemir I. Acute and chronic pretreatment with atenolol attenuates intestinal ischemia and reperfusion injury in hypercholesterolemic rats. J Cardiothorac Vasc Anesth. 2016;30(4):985-92. doi: 10.1053/j.jvca.2016.03.140.

10.Deepak SA, Kottapalli KR, RakwalR, Oros G, Rangappa K, Iwahashi H, Masuo Y, Agrawal G. Real-time PCR: revolutionizing detection and expression analysis of genes. Curr Genomics. 2007;8(4):234-51. PMID: 18645596.

11.Ikejiri AT, Somaio Neto F, Chaves JC, Bertoletto PR, Teruya R, Bertoletto ER, Taha $\mathrm{MO}$, Fagundes DJ. Gene expression profile of oxidative stress in the lung of inbred mice after intestinal ischemia/reperfusion injury. Acta Cir Bras. 2014;29(3):186-92. doi: 10.1590/S0102-86502014000300007.

12.Somaio Neto F, Ikejiri AT, Bertoletto PR, Chaves JC, Teruya R, Fagundes DJ, Taha MO. Gene expression related to oxidative stress in the heart of mice after intestinal ischemia. Arq Bras Cardiol. 2014;102(2):165-73. doi: 10.5935/abc. 20130240.

13.Suski JM1, Lebiedzinska $M$, Bonora $M$, Pinton P, Duszynski J, Wieckowski MR. Relation between mitochondrial membrane potential and ROS formation. Methods Mol Biol. 2012;810:183-205. doi: 10.1007/9781-61779-382-0_12.

14.Ge Y, Yan D, Dēng H, Chen W, An G. Novel Molecular regulators of tumor necrosis factor-related apoptosis-inducing ligand (TRAIL)-induced apoptosis in NSCLC cells. Clin Lab. 2015;61(12):1855-63. PMID: 26882807.

15. Harmalkar M, Upraity S, Kazi S, Shirsat NV. Tamoxifen-induced cell death of malignant glioma cells is brought about by oxidative-stress-mediated alterations in the expression of BCL2 family members and is enhanced on miR-21 inhibition. J 
Mol Neurosci. 2015;57(2):197-202. doi: 10.1007/s12031-015-0602-x.

16.Li YF, Nanayakkara G, Sun Y, Li X, Wang L, Cueto $R$, Shao $Y$, Fu $H$, Johnson $C$, Cheng J, Chen X, Hu W, Yu J, Choi ET, Wang H, Yang XF. Analyses of caspase-1-regulated transcriptomes in various tissues lead to identification of novel IL-1 $\beta-$, IL-18- and sirtuin-1-independent pathways. J Hematol Oncol. 2017;10(1):40. doi: 10.1186/s13045017-0406-2.

\section{Correspondence:}

Murched Omar Taha

Rua Joaquim Távora, 1599/160 andar

04015-003 São Paulo - SP Brasil

Tel.: (55 11)5084-0100 / 99998-2000

Fax: (55 11)5571-0233

taha@uol.com.br

Received: Aug 17, 2018

Review: Oct 20, 2018

Accepted: Nov 23, 2018
Conflict of interest: none

Financial source: none
${ }^{1}$ Research performed at Surgical Techniques Division, Surgery Department, São Paulo Medical School, Universidade Federal de São Paulo (UNIFESP), Brazil. 